\title{
FREQUENCY OF THE IGF A/G rs7136446 POLYMORPHISM AND ATHLETIC PERFORMANCE
}

\author{
Sigal Ben-Zaken ${ }^{1}$, Shir Malach ${ }^{2}$, Yoav Meckel ${ }^{1}$, Dan Nemet ${ }^{2}$, \\ Alon Eliakim ${ }^{2}$ \\ ${ }^{1}$ The Zinman College of Physical Education and Sports Sciences at the Wingate \\ Institute, Genetics and Molecular Biology Laboratory, Netanya, Israel \\ ${ }^{2}$ Meir Medical Center, Child Health and Sports Center, Pediatric Department, \\ Sackler School of Medicine, Tel-Aviv University, Israel
}

\begin{abstract}
Previous studies have shown that carrying the minor T allele of the IGF C-1245T polymorphism was associated with higher circulating IGF-I levels, greater muscle mass and improved power athletic performance. The aim of the present study was to assess the frequency distribution of another IGF-I single nucleotide polymorphism (SNP), the A/G rs7136446, among Israeli athletes. The IGF A/G rs7136446 polymorphism was determined in 185 short $(n=72)$ and long-distance $(n=113)$ runners, 94 short $(\mathrm{n}=44)$ and long-distance $(\mathrm{n}=50)$ swimmers, 54 weight-lifters and 111 controls. There were no significant differences in GG carriers, previously described as associated with higher maximal force production, between the athletes and controls. The only statistical significant difference in GG carriers was found between the sprinters (24\%) and weight-lifters (9\%; $\mathrm{p}<0.05$ ). Although a single polymorphism cannot determine an athlete's ability to succeed or fail in sports, the present findings suggest a potential importance of IGF-I polymorphisms mainly to power sports and in particular to speed sport performance.
\end{abstract}

Keywords: genetic profile; athletic performance; speed sport events

\section{INTRODUCTION}

Directing children to focus in a single sport before adolescence is discouraged. Despite that, an increasing number of children do specialize in specific 
sport at an early age, and even compete in "elite" level. Moreover, several Olympic sports initiate their selection processes in an attempt to identify future champions even before elementary school [13]. Therefore, it seems that one of the key factors for competitive sports success is identification of a sport event that best matches the athlete's ability at a proper age [32]. Recent efforts to identify relevant genes for human athletic excellence are difficult, mainly because each gene makes only a small contribution to the overall heritability. However, genetic polymorphism has been suggested as an additional, sometimes very important, piece in the puzzle of sport selection. The idea that genetic hormonal polymorphism may also be used for prediction of sports excellence has emerged in recent years, and is only in its origins.

It is now well established that changes in insulin-like growth factor-I (IGF-I) play a pivotal role in the muscle adaptation to exercise $[1,9,11$, $14,15,25,28]$. Previous studies in pre and late pubertal girls have shown that both functional (i.e. maximal oxygen consumption - $\mathrm{VO}_{2 \max }$ ) and structural (i.e. thigh muscle volume determined by magnetic resonance images) indices of fitness were correlated with serum IGF-I levels $[10,12]$. Therefore, the majority of studies on hormonal genetic polymorphism and athletic success focused on the IGF-I system. Interestingly, very few studies examined the variation of IGF-I polymorphism in professional athletes. C-1245T (rs35767) is a genetic variation in the promoter region of the IGF-I gene. The minor allele $\mathrm{T}$ is associated with higher circulating IGF-I levels [7, 26, 27]. The frequency of the IGF-I promoter polymorphism was significantly greater among athletes compared to non-active controls with a considerably higher sequence frequency among strength athletes compared to team-sport athletes [20]. Higher $\mathrm{VO}_{2 \max }$ level was found among Polish athlete's carriers of the i88 and i94 allele tandem repeats of the IGF gene polymorphism, while carriers of the i86 allele had lower $\mathrm{VO}_{2 \max }$ levels [16]. Consistent with the previous results, we demonstrated a higher frequency of the T/T polymorphism among Israeli athletes compared to non-existence among controls [4]. While half of the T/T polymorphism carriers were endurance athletes and half power athletes, endurance $\mathrm{T} / \mathrm{T}$ carriers were of national level, but the power athletes were top-level athletes (international and Olympic). This suggested that the IGF-I T/T polymorphism possible association with greater muscle mass is more important to power sport excellence.

The aim of the present study was to assess the frequency distribution of another IGF-I single nucleotide polymorphism (SNP), the A/G, rs7136446, among Israeli athletes. It was previously demonstrated that GG homozygotes of the IGF-I rs7136446 SNP showed higher maximal force production 
compared with the other genotypes, and logistic regression analysis showed that presence of the A allele decreased the odds for higher maximal force production. Therefore, we hypothesized that the prevalence of the GG IGF-I rs7136446 SNP would be higher among the athletes and mainly among the power athletes.

\section{MATERIALS AND METHODS}

\section{Participants}

Two hundred and thirty-nine track and field athletes (182 males and 57 females, age 17-55 years) and 94 swimmers (61 males and 33 females, age 16-49 years) participated in the study. Track and field athletes were assigned to three main sub-groups according to their event speciality during their athletic career: 1) long-distance runners (major event: $5000 \mathrm{~m}$ to marathon run, $\mathrm{n}=113), 2)$ short-distance runners (100-200 $\mathrm{m}$ sprinters and jumpers, $\mathrm{n}=72$ ), and 3) weight lifters (major event: Snatch, Clean and jerk, $\mathrm{n}=54$ ). Swimmers were assigned to two groups according to their main swimming event during their swimming career: 1) long-distance swimmers (major event: 400-1500 m swim, $\mathrm{n}=50$ ), and 2) short-distance swimmers (major event: 50-100 m swim, $n=44$ ). All athletes were ranked among the top alltime Israeli results in their event and had competed at national and/or international level on a regular basis. The control group consisted of 113 (92 males and 21 females, age 20-29 years) non-athletic healthy individuals who were not engaged in competitive sport. Characteristics of the athletes and controls are presented in Table 1.

Table 1. Athletes and controls' data.

\begin{tabular}{lclccc}
\hline Group & $\mathbf{n}$ & Main event & M/F & $\begin{array}{c}\text { Top/ } \\
\text { National } \\
\text { level }\end{array}$ & $\begin{array}{c}\text { Age (Mean } \pm \text { SD, } \\
\text { range) }\end{array}$ \\
\hline Endurance runners & 113 & 5000 m-marathon & $92 / 21$ & $48 / 65$ & $32.4 \pm 9.5(17-55)$ \\
\hline Sprinters/Jumpers & 72 & $100-200 m$, jumps & $49 / 23$ & $28 / 44$ & $30.5 \pm 13.7(17-71)$ \\
\hline Weight lifters & 54 & Snatch, Clean \& Jerk & $41 / 13$ & $34 / 20$ & $28.7 \pm 9.4(17-47)$ \\
\hline $\begin{array}{l}\text { Long distance } \\
\text { swimmers }\end{array}$ & 50 & $400-1500 m$ & $32 / 18$ & $20 / 30$ & $25.3 \pm 9.3(16-48)$ \\
\hline $\begin{array}{l}\text { Short distance } \\
\text { swimmers }\end{array}$ & 44 & $50-100 m$ & & & \\
\hline Controls & 111 & - & $77 / 34$ & - & $26.4 \pm 5.8(19-29)$ \\
\hline
\end{tabular}


The study was approved by the Institutional Review Board of the Hillel Yaffe Medical Center, Hadera, Israel, according to the Declaration of Helsinki. Written informed consent was obtained from each participant before the commencement of the study.

\section{Genotyping}

Genomic DNA was extracted from peripheral EDTA treated anti-coagulated blood using a standard protocol, described elsewhere [24]. Briefly, Lyses buffer $(5 \mathrm{~mL})$ containing $100 \mathrm{mM}$ of tris $\mathrm{HCl}, \mathrm{pH}=8.5+0.5 \mathrm{M}$ of EDTA + $10 \% \mathrm{SDS}+5 \mathrm{M}$ of $\mathrm{NaCl} 40 \mathrm{~mL}$ added D.D.W. to $1000 \mathrm{~mL}$ was added to the white cell solution. Proteinase $\mathrm{K}(200 \mu \mathrm{g})$ was added to the solution. The tubes were incubated at $50^{\circ} \mathrm{C}$ in a shaker incubator for overnight for digestion. After digestion, one volume of ethanol $\left(-20^{\circ} \mathrm{C}\right)$ was added to the lysate and the samples were swirled until precipitation was completed (20-30 min, until it became completely transparent). The DNA was recovered by lifting the aggregated precipitate from the solution, using a disposable tip. Excess liquid was dabbed off and the DNA was dispersed in a pre-labelled eppendorf tube. The DNA was washed in TE solution. Genotypes were determined using the TaqMan allelic discrimination assay. The Assay-by-Design service (http://www.thermofisher.com) was used to set up a TaqMan allelic discrimination assay for the IGF1 A/G (rs7136446).

Primer sequences were forward: AATTGGTTACCTGCTACATTGA, reverse: G GAGTTAACGCATCTCCTTACTG. Probe sequences were for $-174 \mathrm{G} / \mathrm{C}$ forward: VIC- CGCGTAGTCGAGCG, reverse: FAMCGCTCGCTGCCCTAAGTGCT. The PCR reaction mixture included $5 \mathrm{ng}$ genomic DNA, $0.125 \mu$ l TaqMan assay $\left(40^{\star}, \mathrm{ABI}\right), 2.5 \mu$ l Master mix (ABI) and $2.375 \mu \mathrm{l}$ water. PCR was performed in 96 well PCR plates in an ABI 7300 PCR system (Applied Biosystems Inc., Foster City, CA, USA) and consisted of initial denaturation for $5 \mathrm{~min}$ at $95^{\circ} \mathrm{C}$, and 40 cycles with denaturation of $15 \mathrm{~s}$ at $95^{\circ} \mathrm{C}$ and annealing and extension for $60 \mathrm{~s}$ at $63^{\circ} \mathrm{C}$. Results were analyzed by the ABI TaqMan $7900 \mathrm{HT}$ using the sequence detection system 2.22 software (Applied Biosystems Inc.).

\section{Statistical analysis}

The SPSS statistical package, version 20.0, was used to perform all statistical analyses (SPSS, Chicago, IL, USA). A $\chi^{2}$-test was applied to confirm that the observed genotype frequencies were within the Hardy-Weinberg equilibrium and to compare allele and genotype frequencies between athletes and controls, as well as between athletes from different sports and between different competitive groups (e.g. short versus long-distance). If observed or 
expected values included a cell with a value of 5, we used a Fisher's exact test to compare allele and genotype frequencies.

\section{RESULTS}

The prevalence of the A/G IGF-I rs7136446 single nucleotide polymorphism among Israeli long and short distance runners and swimmers and among weight lifters is shown in Table 2 and Figure 1. Genotype subtype did not differ by age or sex. In addition, IGF-I A/G genotype distribution was in agreement with the Hardy-Weinberg equilibrium within all groups $(\mathrm{p}>0.05)$.

Table 2. The prevalence of the A/G IGF-I rs7136446 polymorphism among Israeli long and short distance runners and swimmers and among weight lifters.

\begin{tabular}{|c|c|c|c|c|c|c|c|c|c|c|c|}
\hline & \multirow{3}{*}{$\mathbf{n}$} & \multicolumn{6}{|c|}{ Genotype frequencies } & \multicolumn{4}{|c|}{ Allele frequencies } \\
\hline & & \multicolumn{2}{|c|}{ AA } & \multicolumn{2}{|c|}{ AG } & \multicolumn{2}{|c|}{ GG } & \multicolumn{2}{|c|}{ A - allele } & \multicolumn{2}{|c|}{ G - allele } \\
\hline & & $\mathrm{N}$ & $\%$ & $\mathrm{~N}$ & $\%$ & $\mathrm{~N}$ & $\%$ & $\mathrm{~N}$ & $\%$ & $\mathrm{~N}$ & $\%$ \\
\hline Control & 111 & 45 & $41 \%$ & 50 & $45 \%$ & 16 & $14 \%$ & 140 & $63 \%$ & 82 & $37 \%$ \\
\hline
\end{tabular}

Endurance Runners

\begin{tabular}{r|c|cc|cc|cc|cc|cc}
\hline Top level & 48 & 18 & $38 \%$ & 23 & $48 \%$ & 7 & $15 \%$ & 59 & $61 \%$ & 37 & $39 \%$ \\
\hline National level & 65 & 28 & $43 \%$ & 26 & $40 \%$ & 11 & $17 \%$ & 82 & $63 \%$ & 48 & $37 \%$ \\
\hline Total & 113 & 46 & $41 \%$ & 49 & $43 \%$ & 18 & $16 \%$ & 141 & $62 \%$ & 85 & $38 \%$ \\
\hline
\end{tabular}

Sprinters and Jumpers

\begin{tabular}{r|c|cc|cc|cc|cc|cc}
\hline Top level & 28 & 9 & $32 \%$ & 13 & $46 \%$ & 6 & $21 \%$ & 31 & $55 \%$ & 25 & $45 \%$ \\
\hline National level & 44 & 15 & $34 \%$ & 18 & $41 \%$ & 11 & $25 \%$ & 48 & $55 \%$ & 40 & $45 \%$ \\
\hline Total & 72 & 24 & $33 \%$ & 31 & $43 \%$ & 17 & $24 \%$ & 79 & $55 \%$ & 65 & $45 \%$ \\
\hline
\end{tabular}

\section{Weight Lifters}

\begin{tabular}{r|c|cc|cc|cc|cc|cc}
\hline Top level & 34 & 15 & $44 \%$ & 15 & $44 \%$ & 4 & $12 \%$ & 45 & $66 \%$ & 23 & $34 \%$ \\
\hline National level & 20 & 5 & $25 \%$ & 14 & $70 \%$ & 1 & $5 \%$ & 24 & $60 \%$ & 16 & $40 \%$ \\
\hline Total & 54 & 20 & $37 \%$ & 29 & $54 \%$ & 5 & $9 \%$ & 69 & $64 \%$ & 39 & $36 \%$ \\
\hline
\end{tabular}

Short distance swimmers

\begin{tabular}{r|c|cc|cc|cc|cc|cc}
\hline Top level & 10 & 4 & $40 \%$ & 5 & $50 \%$ & 1 & $10 \%$ & 13 & $65 \%$ & 7 & $35 \%$ \\
\hline National level & 34 & 11 & $32 \%$ & 18 & $53 \%$ & 5 & $15 \%$ & 40 & $59 \%$ & 28 & $41 \%$ \\
\hline Total & 44 & 15 & $34 \%$ & 23 & $52 \%$ & 6 & $14 \%$ & 53 & $60 \%$ & 35 & $40 \%$ \\
\hline
\end{tabular}

Long distance swimmers

\begin{tabular}{r|c|cc|cc|cc|cc|cc}
\hline Top level & 20 & 7 & $35 \%$ & 12 & $60 \%$ & 1 & $5 \%$ & 26 & $65 \%$ & 14 & $35 \%$ \\
\hline National level & 30 & 11 & $37 \%$ & 11 & $37 \%$ & 8 & $27 \%$ & 33 & $55 \%$ & 27 & $45 \%$ \\
\hline Total & 50 & 18 & $36 \%$ & 23 & $46 \%$ & 9 & $18 \%$ & 59 & $59 \%$ & 41 & $41 \%$ \\
\hline
\end{tabular}




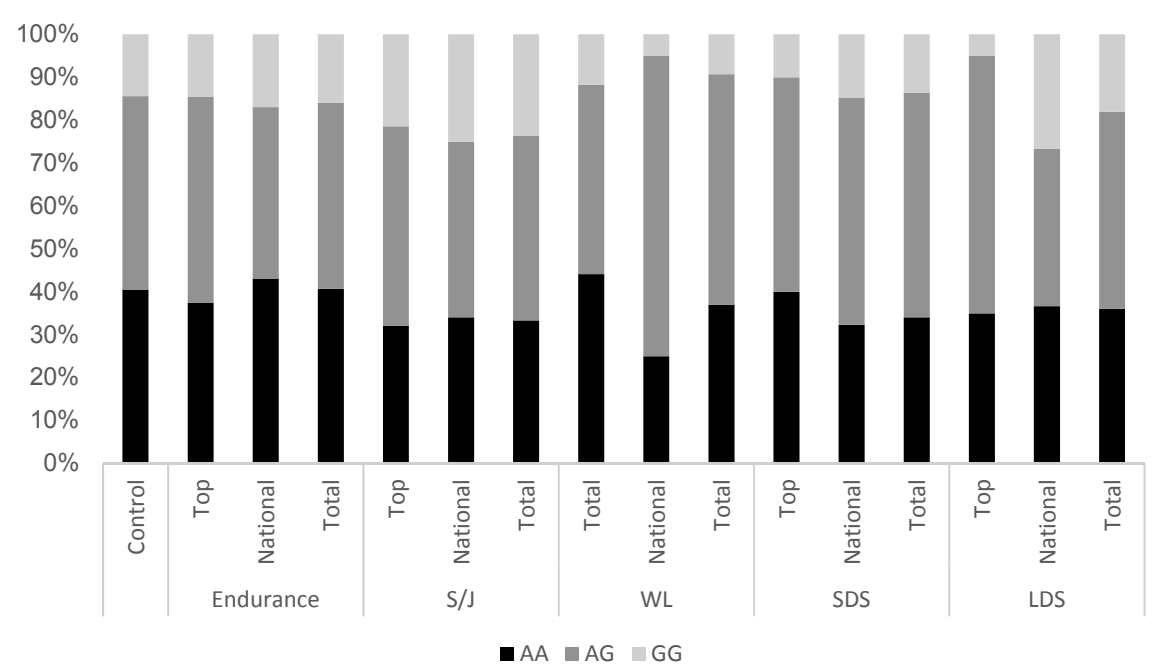

Figure 1. The prevalence of the A/G IGF-I rs7136446 polymorphism among national and top level Israeli long and short distance runners and swimmers and among weight lifters. Note: $\chi 2(1)=4.41, p=0.036$, for GG genotype frequency, sprinters vs. weight lifters.

The higher prevalence of IGF-I rs7136446 GG genotype was found among sprinters and jumpers $(21 \%, 25 \%$, and $24 \%$ for top-, national-level and total, respectively); while the lower GG genotype frequencies were found among weight lifters $(12 \%, 5 \%$, and $9 \%$ for top-, national-level and total, respectively, $\mathrm{p}<0.05)$.

IGF-I rs7136446 GG genotype frequencies among endurance runners, swimmers and controls vary between 10 to $18 \%$, and were similar to the prevalence found among healthy Finnish males [17]. There were no significant differences in GG genotype carriers between short and long-distance runners and controls, between short and long-distance swimmers and controls, and between weight-lifters and controls. Also, there was no difference in IGF-I rs7136446 GG genotype frequencies between top and national level for all groups.

\section{DISCUSSION}

We examined the prevalence of the A/G IGF-I rs7136446 polymorphism among Israeli long and short distance runners and swimmers and among weight lifters. In contrast to our hypothesis, there were no significant differences in GG carriers between athletes (runners - short and long-distance, swimmers - short and long-distance, and weight-lifters) and controls. 
However, interestingly, the prevalence of GG carriers was significantly greater among sprinters compared to weight-lifters suggesting that carrying this polymorphism is beneficial mainly for speed rather than strength sport events.

The effect of IGF-I polymorphism on muscle mass and fitness characteristics has been studied mainly among the elderly because of the age-related decrease in muscle mass and strength $[22,30]$, and the consequent reduction in functional abilities, increased risk of falling and fractures [21, 29]. Since the IGF-I gene regulates muscle hypertrophy, several studies have focused on the relationship between IGF-I polymorphism, IGF-I levels, muscle mass, and physical ability. The majority of these studies have demonstrated a significant relationship between the IGF 1245T SNP and both baseline fat free mass (FFM) and FFM response to training in the elderly population [8, $18,19,31]$.

Surprisingly, very few studies have examined variation in IGF-I polymorphism among professional athletes [20]. The frequency of the IGF-I promoter polymorphism was significantly greater among athletes $(9.2 \%)$ compared to non-active controls (2.4\%). Moreover, among the athletes, a substantially higher sequence frequency was found among strength (11\%) compared to team-sport athletes (7.8\%). We previously demonstrated [4] in a cohort of Israeli athletes a higher frequency of the IGF C1245T T/T polymorphism among athletes $(4.8 \%)$, while none of the control participants carried that polymorphism. Interestingly, half of the T/T polymorphism carriers were endurance athletes and half were power athletes. However, despite the equal distribution among endurance and power athletes, one of the most striking finding of the study was that while the endurance athletes with the T/T polymorphism were of national level, the power athletes were elite-level athletes (international and Olympic). The results suggested that the IGF-I T/T polymorphism possible association with muscle mass increase is more important to power sport performance and excellence. The main contribution of the present study assessing the frequency of another polymorphism of the IGF-I gene (i.e. IGF-I rs7136446) is that carrying the GG genotype was significantly more frequent among sprinters compared to weight lifters. All together this may suggest that among power sports, IGF-I polymorphism is more important to speed rather than strength athletes. Previous studies have demonstrated other polymorphism frequency differences between speed oriented and strength oriented athletes [3].

It is very frequent in sports genetic research to combine athletes from different sports-types but with similar metabolic demands (e.g. endurance 
athletes: long-distance running, swimming, cycling and triathlon; power athletes: sprinting, jumping and weight lifting). Interestingly, we did not find a higher frequency of the IGF-I rs7136446 GG polymorphism among swimmers. This is consistent with our previous reports demonstrating that in contrast to elite endurance and power track and field athletes, single nucleotide polymorphisms of IGF-I and the IGF-I receptor and myostatin were not frequent among elite Israeli short- and long-distance swimmers [2, 4-6]. These results may indicate rather uniquely that the myostatin-IGF-I-IGF-I receptor growth factor system is less important for competitive swimming and elite swimming performance than for runners. The mechanism that may explain the different role of myostatin-IGF-I-IGF-I receptor growth factor system polymorphism in swimming compared to running performance is currently unknown. One possible explanation is that excellence in swimming is largely affected by the swimming technique and by the swimmer's size (particularly limb length) [23] which may, at least partially, mask metabolic and muscle mass differences between swimmers, enabling technically-skilled and/or tall swimmers to excel at all swimming distances, and particularly in the sprints. All together these results indicate that different sports disciplines (e.g. swimming and track and field) may have different genetic polymorphisms, despite seemingly similar metabolic characteristics. Thus, it should be acknowledged that combining different disciplines for sports genetic research purposes should not be done, or at least be done with extreme caution.

In summary, although it is well recognized that a single polymorphism cannot determine an athlete's ability to succeed or fail in sports, the findings suggest a potential importance of IGF-I polymorphisms mainly to power sports and in particular to speed sport performance in athletes. Whether a multi-potent athlete who wants to develop a competitive career and carries a beneficial IGF-I polymorphism should prefer track and field over swimming is currently hypothetical and speculative. Moreover, one should acknowledge that while a favourable genetic predisposition is important, psychological and environmental aspects, including training equipment and facilities, nutrition, familial support, and motivational issues, are also crucial for elite-level sports accomplishment. 


\section{REFERENCES}

1. Bamman MM, Petrella JK, Kim J, Mayhew DL, Cross JM. (2007) Cluster analysis tests the importance of myogenic gene expression during myofiber hypertrophy in humans. J Appl Physiol, 102: 2232-2239.

2. Ben Zaken S, Meckel Y, Dror N, Nemet D, Eliakim A. (2014) IGF-I and IGF-I receptor polymorphisms among elite swimmers. Pediatr Exerc Sci, 26: 470-476.

3. Ben-Zaken S, Eliakim A, Nemet D, Meckel Y. (2016) Genetic variability among power athletes: The stronger vs. the faster. J Strength Cond Res (In Press).

4. Ben-Zaken S, Meckel Y, Nemet D, Eliakim A. (2013) Can IGF-I polymorphism affect power and endurance athletic performance? Growth Horm IGF Res, 23: 175-178.

5. Ben-Zaken S, Meckel Y, Nemet D, Eliakim A. (2015) IGF-I receptor 275124A $>C$ (rs1464430) polymorphism and athletic performance. J Sci Med Sport, 18: 323327.

6. Ben-Zaken S, Meckel Y, Nemet D, Rabinovich M, Kassem E, Eliakim A. (2015) Frequency of the MSTN Lys(K)-153Arg(R) polymorphism among track \& field athletes and swimmers. Growth Horm IGF Res, 25: 196-200.

7. Canzian F, McKay JD, Cleveland RJ, Dossus L, Biessy C, Rinaldi S, Landi S, Boillot C, Monnier S, Chajès V, Clavel-Chapelon F, Téhard B, Chang-Claude J, Linseisen J, Lahmann PH, Pischon T, Trichopoulos D, Trichopoulou A, Zilis D, Palli D, Tumino R, Vineis P, Berrino F, Bueno-de-Mesquita HB, van Gils CH, Peeters PH, Pera G, Ardanaz E, Chirlaque MD, Quirós JR, Larrañaga N, MartínezGarcía C, Allen NE, Key TJ, Bingham SA, Khaw KT, Slimani N, Norat T, Riboli E, Kaaks R. (2006) Polymorphisms of genes coding for insulin-like growth factor 1 and its major binding proteins, circulating levels of IGF-I and IGFBP-3 and breast cancer risk: results from the EPIC study. Br J Cancer, 94: 299-307.

8. Chagnon YC, Rice T, Pérusse L, Borecki IB, Ho-Kim MA, Lacaille M, Paré C, Bouchard L, Gagnon J, Leon AS, Skinner JS, Wilmore JH, Rao DC, Bouchard C. (2001) Genomic scan for genes affecting body composition before and after training in Caucasians from HERITAGE. J Appl Physiol, 90: 1777-1787.

9. Coleman ME, DeMayo F, Yin KC, Lee HM, Geske R, Montgomery C, Schwartz RJ (1995) Myogenic vector expression of insulin-like growth factor I stimulates muscle cell differentiation and myofiber hypertrophy in transgenic mice. J Biol Chem, 270: 12109-12116.

10. Eliakim A, Brasel JA, Mohan S, Barstow TJ, Berman N, Cooper DM. (1996) Physical fitness, endurance training, and the growth hormone-insulin-like growth factor I system in adolescent females. J Clin Endocrinol Metab, 81: 3986-3992.

11. Eliakim A, Nemet D. (2010) Exercise training, physical fitness and the growth hormone-insulin-like growth factor-1 axis and cytokine balance. Med Sport Sci, 55: $128-140$. 
12. Eliakim A, Scheett TP, Newcomb R, Mohan S, Cooper DM. (2001) Fitness, training, and the growth hormone->insulin-like growth factor I axis in prepubertal girls. J Clin Endocrinol Metab, 86: 2797-2802.

13. Gonçalves C EB, Rama L ML, Figueiredo AB. (2012) Talent identification and specialization in sport: an overview of some unanswered questions. Int J Sports Physiol Perform, 7: 390-393.

14. Gonzalez E, Messi ML, Zheng Z, Delbono O. (2003) Insulin-like growth factor-1 prevents age-related decrease in specific force and intracellular $\mathrm{Ca} 2+$ in single intact muscle fibres from transgenic mice. J Physiol, 552: 833-844.

15. Greig CA, Hameed M, Young A, Goldspink G, Noble B. (2006) Skeletal muscle IGF-I isoform expression in healthy women after isometric exercise. Growth Horm IGF Res, 16: 373-376.

16. Gronek P, Holdys J, Kryściak J, Wieliński D, Słomski R. (2014) Maximal oxygen uptake is associated with allele $-202 \mathrm{~A}$ of insulin-like growth factor binding protein-3 (IGFBP3) promoter polymorphism and (CA)n tandem repeats of insulin-like growth factor IGF1 in Caucasians from Poland. Acta Biochim Pol, 61: 245-252.

17. Huuskonen A, Lappalainen J, Oksala N, Santtila M, Häkkinen K, Kyröläinen H, Atalay M. (2011) Common genetic variation in the IGF1 associates with maximal force output. Med Sci Sports Exerc, 43: 2368-2374.

18. Kostek MC, Delmonico MJ, Reichel JB, Roth SM, Douglass L, Ferrell RE, Hurley BF. (2005) Muscle strength response to strength training is influenced by insulin-like growth factor 1 genotype in older adults. J Appl Physiol, 98: 2147-2154.

19. Kostek MC, Devaney JM, Gordish-Dressman H, Harris TB, Thompson PD, Clarkson PM, Angelopoulos TJ, Gordon PM, Moyna NM, Pescatello LS, Visich PS, Zoeller RF, Seip RL, Garcia M, Li R, Zmuda JM, Delmonico MJ, Kanaya A, Hoffman EP. (2010) A polymorphism near IGF1 is associated with body composition and muscle function in women from the Health, Aging, and Body Composition Study. Eur J Appl Physiol, 110: 315-324.

20. Krych-Garsztka K, Mizgajska-Wiktor H, Gozdzucka-Jojefiak A. (2011) An analysis of the regulatory region of the IGF1 gene in professional athletes in youth sports teams. Hum Mov, 12: 216-222.

21. Lord SR, Ward JA, Williams P, Anstey KJ. (1994) Physiological factors associated with falls in older community-dwelling women. J Am Geriatr Soc, 42: 1110-1117.

22. Lynch NA, Metter EJ, Lindle RS, Fozard JL, Tobin JD, Roy TA, Fleg JL, Hurley BF. (1999) Muscle quality. I. Age-associated differences between arm and leg muscle groups. J Appl Physiol, 86: 188-194.

23. Maglischo E. (2003) Swimming Fastest. Human Kinetics.

24. Miller SA, Dykes DD, Polesky HF. (1988) A simple salting out procedure for extracting DNA from human nucleated cells. Nucleic Acids Res, 16: 1215. 
25. Nemet D, Eliakim A. (2010) Growth hormone-insulin-like growth factor-1 and inflammatory response to a single exercise bout in children and adolescents. Med Sport Sci, 55: 141-155.

26. Palles C, Johnson N, Coupland B, Taylor C, Carvajal J, Holly J, Fentiman IS, Silva Idos S, Ashworth A, Peto J, Fletcher O. (2008) Identification of genetic variants that influence circulating IGF1 levels: a targeted search strategy. Hum Mol Genet, 17: 1457-1464.

27. Patel AV, Cheng I, Canzian F, Le Marchand L, Thun MJ, Berg CD, Buring J, Calle EE, Chanock S, Clavel-Chapelon F, Cox DG, Dorronsoro M, Dossus L, Haiman CA, Hankinson SE, Henderson BE, Hoover R, Hunter DJ, Kaaks R, Kolonel LN, Kraft P, Linseisen J, Lund E, Manjer J, McCarty C, Peeters PH, Pike MC, Pollak M, Riboli E, Stram DO, Tjonneland A, Travis RC, Trichopoulos D, Tumino R, Yeager M, Ziegler RG, Feigelson HS; Breast and Prostate Cancer Cohort Consortium. (2008) IGF-1, IGFBP-1, and IGFBP-3 polymorphisms predict circulating IGF levels but not breast cancer risk: findings from the Breast and Prostate Cancer Cohort Consortium (BPC3). PLoS One, 2008;3: e2578.

28. Powell-Braxton L, Hollingshead P, Warburton C, Dowd M, Pitts-Meek S, Dalton D, Gillett N, Stewart TA. (1993) IGF-I is required for normal embryonic growth in mice. Genes Dev, 7: 2609-2617.

29. Rantanen T, Era P, Heikkinen E. (1997) Physical activity and the changes in maximal isometric strength in men and women from the age of 75 to 80 years. J Am Geriatr Soc, 45: 1439-1445.

30. Reed RL, Pearlmutter L, Yochum K, Meredith KE, Mooradian AD. (1991) The relationship between muscle mass and muscle strength in the elderly. J Am Geriatr Soc, 39: 555-561.

31. Sun G, Gagnon J, Chagnon YC, Pérusse L, Després JP, Leon AS, Wilmore JH, Skinner JS, Borecki I, Rao DC, Bouchard C. (1999) Association and linkage between an insulin-like growth factor-1 gene polymorphism and fat free mass in the HERITAGE Family Study. Int J Obes Relat Metab Disord, 23: 929-935.

32. Valovich McLeod TC, Decoster LC, Loud KJ, Micheli LJ, Parker JT, Sandrey MA, White C. (2011) National Athletic Trainers' Association position statement: prevention of pediatric overuse injuries. J Athl Train, 46: 206-220.

\section{Correspondence to:}

Prof. Alon Eliakim, MD

Department of Pediatrcs

Mei Medical Center

Sackler School of Medicine

Tel Aviv University, Israel

Telephone: +97297471596

Fax: +97297471303

Email: eliakim.alon@clalit.org.il 